\title{
Study of Financial Investment Risk Assessment and Its Revenue
}

\author{
Bo Sun ${ }^{1, a}$, Haotian Liu ${ }^{2, b}$ \\ ${ }^{1}$ Shandong Youth University of Political Science, School of Economics and Management, Jinan, \\ Shandong, 250000 \\ ${ }^{2}$ Agricultural Bank of China Shandong Branch, Jinan, Shandong, 250000
}

Keywords: Financial Investment, Risk Assessment, Revenue

\begin{abstract}
With Chinese accession to the WTO, the links between countries closer, making international financial investment, coupled with a variety of financial investment companies mushroomed, as well as a variety of financial investment tools, which greatly promoted the Financial investment market, but because the financial investment by the national policy, financial market environment, economic law and other factors, making financial investment there is a great risk, so how to maximize the return on investment has been the financial investment The pursuit of the goal.
\end{abstract}

\section{Introduction}

Financial investment is a concept of commodity economy, referring to the use of natural persons or units of disposable funds to purchase financial goods, in order to obtain the risk is proportional to the economic benefits, is also an important part of modern investment concept. Financial investment is in accordance with the different standards, with different types of financial investment. It is divided into direct investment and indirect financing by investment, divided into long-term investment and short-term investment in accordance with the length of time, according to the nature of the fixed-income investment and non-fixed income investment. Financial investment is different from the physical investment, financial investment is the main investor of indirect investors and capital providers to deposits or securities and other financial assets as the investment object to achieve the value-added financial assets, capital investment, and in-kind The main investors of the investment are direct investors and capital demanders, and various physical investment assets are taken as investment objects, including workshops, raw materials, etc., and engage in production and business activities to obtain production and operation profits. Financial investment provides financial support for physical investment. Physical investment is the source of financial investment income. The two are both differentiated and closely linked. They are the main components of the current investment market.

There are more than 10 kinds of domestic financial investment products, such as bank deposit, fund, stock, bond and foreign exchange investment, and precious metal investment. This paper introduces several common types of financial investment: 1. Bank deposits. Bank deposits are divided into personal bank deposits and corporate bank deposits, refers to the money in the bank, the bank regularly to the corresponding interest rate, bank deposits are all types of financial investment in the least risky, easy to operate, but the relative return Is relatively low. 2. Funds. Fund has a broad and narrow sense, the broad fund mainly includes trust and investment funds, provident funds, insurance funds, pension funds for a purpose such as the establishment of a certain amount of funds, the narrow sense of the fund refers to the securities investment fund is also called collection Securities investment is a kind of benefit-sharing, risk-sharing investment, relatively strong liquidity, the income is more objective but also accompanied by a lot of financial investment risk. 3. Stocks. Stock investors in the stock to raise capital issued shares of the certificate, the financial investors to receive dividends or dividends to share a huge investment income, but also to share the company's operational errors caused by high-risk, is the capital market The main long-term credit tools, in addition, investors can not request the company to return its capital, is a high-risk and high-yield financial investment types, and because the operation is relatively simple, is currently many residents choose financial investment goods. 


\section{Financial Investment Risk and Income Problems}

At present, Chinese professional financial investors is relatively small, most of the financial investors with their own speculation or online data analysis and follow others to invest, so most of the financial investment is blind, the lack of long-term planning and thoughtful Consider, and not according to the laws of commodity value reasonable scientific investment, making a lot of financial investors lose everything. This blind investment not only brings huge economic losses to investors, but also disrupts the normal development of the financial economy and hinders the long-term development of the market economy.

In order to avoid the risk of financial investment, we should invest in financial investment in different financial products, the dispersion of financial investment, to avoid the greatest degree of financial investment risk, but many current financial investors want to financial investment Market access to some of the benefits, but also hope that the financial investment is simple and easy to operate, so many financial investors in order to facilitate investment in the investment focus, the funds invested in one or several very few financial investment products, and thus An increase of financial investment risk.

At present, Chinese financial investors in the investment there are chances, more concerned about the short-term financial investment income, the lack of long-term financial investment income planning and distribution and risk aversion and commitment, resulting in the occurrence of two kinds of investment, One is that as long as there is little change in financial markets will end their investment behavior, completely follow the current changes in the financial market to determine their own investment behavior, the other is completely ignore the financial market changes, even if there is a great risk But always think of struggling to a stroke is still to invest in their own financial investment behavior is not responsible for man-made increase in financial investment risk. These two types of investors are easy to be some financial capitalists to use their psychological black-box operation, undermine the financial investment market economic order.

\section{The Dialectical Relationship between Financial Investment Return and Risk}

In the premise of the development of market economy, financial investment generally has a dual nature, that is, investment returns and risk! Investors optimize the investment goal is to maximize investment income and minimum investment risk, but because the risk and return objective Existence, profit and loss degree will change with time, investment income and investment returns are interdependent and interactive.

Profitability of Financial Investments In financial markets, the yield of financial assets is measured by the rate of return! The rate of return refers to a random variable that measures the popularity of the investment business, that is, the return on investment, which can be measured by mathematical expectations! Different financial instruments Of the rate of return is different, generally in accordance with the time can be divided into the annual rate of return and monthly yield, yield maximization, investors always pursue the goal.

Risk and risk of financial investment refers to the possibility that a financial investor may suffer losses (negative effect of risk) or profit (positive effect of risk) in financial investment activities, and this possible loss or profit is caused by various uncertainties the impact of financial investment results.

According to the different factors, the risk can be divided into interest rate risk and stock market risk, interest rate risk is due to changes in interest rates caused by the decline in the market value of investment goods risk; stock market risk is fluctuated by the stock market price fluctuations caused by a risk Investors generally pursue the risk of financial investment tools can be minimal.

\section{Measures to Avoid Investment Risks and Raise Investment}

Financial investors and financial investment market are closely related to each other, on the one hand, financial investors are based on the situation of financial investment market to invest, on the 
other hand, financial investment behavior to a certain extent, will affect the financial investment market development and Order, so it is necessary to strengthen the management of financial investment market for financial investors to provide a good fair and just investment environment to safeguard the legitimate interests of financial investors to help financial investors to make a reasonable investment to promote the smooth financial investment activities Carry out and promote the overall development of financial markets, to achieve the common development of the two. The main need to start from the following two aspects: First, the state needs to develop and improve the financial investment laws and regulations, so that law enforcement departments have the law, Chinese current financial regulatory framework "line of three" or "line" for the Chinese people Banks, the "three sessions" is the China Banking Regulatory Commission, the China Securities Regulatory Commission, the China Insurance Regulatory Commission, the need to strictly abide by laws and regulations to improve supervision of financial markets, crack down on financial speculators and black-box operators of illegal activities, so that lawless elements without legal loopholes Second, financial investors need to invest rationally, so that investment behavior becomes scientific and rational, to avoid being used by criminals, disrupting the healthy development of financial markets.

Financial investment is a market economic behavior will naturally be affected by environmental policies, especially the state through administrative means and legal instruments promulgated some of the policies based on the current market economy based on the status of the promulgated, so many policy changes are There are practical significance and reference, so through the policy environment concerns, you can learn from the current perspective of some of the current financial and investment prospects, such as when the bank interest rates can choose to bank deposits, bank interest rates can be reduced when the bank deposit The choice of other types of financial investment, as well as changes in the CPI index, foreign exchange regulatory changes in financial policy may have an impact on financial investment income, so the financial investors need to focus on policy environment changes, a reasonable choice of some financial investment products, thus avoiding some Financial investment risk, improve the financial investment income.

Financial investment behavior, although a great deal of randomness, but in seemingly random surface, in fact, contains a lot of economic laws, and many senior investors are able to benefit from financial investment in high yield is as far as possible in the basis These economic laws on the basis of financial investment, these economic laws are not only through the grasp of some theoretical knowledge can be grasped, the need is long-term financial investment practice, so for many beginning financial investors, Can learn from some of the experience of senior investors to improve the scientific nature of financial investment behavior, to develop a reasonable investment program, to a certain extent, to avoid some of the investment risk.

The current financial investment market often appears overnight bankrupt companies and individuals, the reason why such a situation occurs because the financial investors do not invest in their own time from the actual situation of investment, excessive emphasis on high-yield financial investment, Consider their own actual situation can bear the corresponding high-risk, so the financial investors really have to bear the corresponding financial investment risk when they can not afford to eventually lead to bankruptcy, not only for their work and life impact will also affect the other Of people's lives, such as family members, employees, etc., is not conducive to the development of social stability. In addition, many financial investors in the investment did not conduct an effective risk inspection and risk assessment, so some of the financial investment risks and benefits do not have a whole understanding, leading to financial investment failure. More importantly, financial investors should invest in a decentralized investment approach, is the traditional sense of "not to put eggs in a basket," decomposition of risk, so as to avoid desperate after the failure of a huge economic losses.

Technical analysis refers to the summing up of the full study of market behavior as a basis for judging market trends and following cyclical changes in trends to make stock and all financial derivatives trading decisions. Technical analysis methods include index class, tangent class, morphological class, K-type and wave class five, represented by the theory of Dow theory, wave 
theory and Gann theory. Dow's theory holds that the stock market can be analyzed from three aspects: the main trend, the minor changes and the daily changes. The motivators of the stock market include the cyclical crises of the economy, investors' imitation of investment information and stock market information transmission. And so on. Therefore, financial investors should restrict their investment behavior, and use the effective market information and market trend in the technical analysis method to guide the financial investment behavior, so as to avoid the risk of some investment. Technical analysis of the stock market that there are certain changes in the cycle and the law, the financial investors need only a certain period of time to grasp the law of the stock market, "homeopathic and timely error correction", technical analysis of the market reaction faster, but consider The scope of the object is relatively narrow, the long-term market trends difficult to effectively determine the technical analysis method is more applicable to the study of long-term stock market prices and short-term changes in investment behavior for financial investors looking for trading points to improve the probability of successful transactions, Increase the financial investment income.

\section{Conclusion}

With the further development of Chinese market economy reform, the financial market will become more mature, financial investment tools will gradually enrich and perfect, to provide investors with more choices! In the actual financial investment, investors must pay attention to according to The risk of their own different levels of preference and the financial situation to choose a reasonable financial investment program! At the same time, the state must strengthen the supervision of financial investment, improve the financial investment regulatory regime and the corresponding laws and regulations to ensure that financial investment market can be sustained Healthy development, contribute to the development of Chinese economy.

\section{References}

[1] Liu Xiao. Dynamic VaR and ES Calculations Based on POT-APARCH-M-t [J]. China Securities Futures. 2012 (02)

[2] Yang Qing. Application of CVAR-EVT and BMM in Extreme Financial Risk Management [J]. Statistical Research, 2010 (06)

[3] Gao Yuelin, Miao Shiqing. M-V Portfolio Optimization Model Based on VAR and CVAR Risk Control [J]. Statistics \& Decision, 2009 (11)

[4] Zhou Shihao, Ni Yansen. Improved PSO algorithm for solving CVAR portfolio optimization problem [J]. Journal of Wuhan University of Technology, 2010 (01)

[5] Wan Zhongping. Study on the Two-level Newsboy Model under CVaR [J]. Acta Automatica Sinica, 2008 